\title{
Cathodic protection of reinforcement in concrete - experience and development over 30 years
}

\author{
Rob Polder $^{1,2^{*}}$, and Willy Peelen ${ }^{3}$ \\ ${ }^{1}$ RPCP, Fluwelensingel 106, 2806 CH Gouda, The Netherlands \\ ${ }^{2}$ Delft University of Technology, Civil Engineering and Geosciences, Delft, The Netherlands \\ ${ }^{3}$ TNO Technical Sciences/Structural Reliability, Delft, The Netherlands
}

\begin{abstract}
This paper presents developments over 30 years in the field of cathodic protection of steel reinforcement in concrete in The Netherlands and elsewhere. From the late 1980s major developments have been: application to large numbers of precast elements corroding due to mixedin chloride with drilled in titanium anodes and conductive coatings; analysis of working life of systems and components and end-of-life considerations; application to prestressed structures; new anode types including galvanic systems with associated life and design considerations; numerical modelling and preventative applications. Presently, CP has become a fully accepted method of securing safety and serviceability of buildings and infrastructure. Major successes and lessons learned will be presented. Technical and non-technical developments are highlighted and some recent innovative $\mathrm{CP}$ systems are discussed.
\end{abstract}

\section{Introduction}

More and more reinforced concrete structures develop corrosion of the embedded steel. This is due to long-term exposure to aggressive influences such as chlorides from sea water and de-icing salts or to the effects of mixed-in chlorides; in some cases aggravated by carbonation [1, 2]. Older structures are more sensitive to corrosion due to lower cover depths and lower concrete quality than that which is used nowadays. Steel reinforcement corrosion causes cracking and spalling of concrete and steel cross section loss, compromising serviceability and eventually structural safety. Consequently, repair and protection of concrete structures has become a major industry in the past 30 years. However, in many cases conventional methods of concrete repair have been shown to be ineffective or not durable [3,4]. Cathodic protection (CP) on the other hand, has widely been found to be an effective and durable method for protection of steel in concrete. This paper reports on the history and experience with $\mathrm{CP}$ of concrete structures, based on the authors' involvement in The Netherlands and documentation from elsewhere.

$\mathrm{CP}$ of concrete structures was developed in the USA in the 1970s [5] and introduced in Europe in the 1980s [6]. In the USA, a large number of concrete bridge decks was damaged by corrosion due to chloride ingress from de-icing salts. Various types of anodes, including cast iron, coke breeze in asphalt and slotted systems with various mortars, were applied with varying results; many of these early anode types have been discontinued [7]. Next, new anode materials became available, such as activated titanium and conductive coatings, variants of which are still widely used today; sacrificial (galvanic) anodes were introduced in the late 1990s. From about 1985 in the UK [6], Italy [8], Norway [9, 10], Denmark, Switzerland [11, 12] and The Netherlands [13] application of $\mathrm{CP}$ to concrete increased. Increasing numbers of systems are being installed more recently in Germany, France, Belgium and Switzerland. Long term performance and an overview of interventions (repairs) of large numbers of systems have been analysed [14, 15].

\section{Principles}

Reinforcing and prestressing steel in concrete are normally passivated due to the high alkalinity in the pore solution, caused by dissolved potassium and sodium hydroxides and buffered by solid calcium hydroxide at $\mathrm{pH}$ values above 13. With passivation, corrosion is negligible and very low rates of oxidation and reduction occur. In aerated concrete potentials of about +0 to -100 $\mathrm{mV}$ versus a saturated calomel electrode (SCE) are present. Lowering of the $\mathrm{pH}$ due to carbonation, a reaction with carbon dioxide from the atmosphere, or the presence of chloride ions above a certain threshold concentration cause depassivation and initiation of corrosion. Subsequently anodic (oxidation) reactions and cathodic (reduction) reactions are strongly accelerated versus the passive state, respectively described by the following equations:

$$
\begin{array}{r}
\mathrm{Fe} \rightarrow \mathrm{Fe}^{2+}+2 e \\
2 \mathrm{H}_{2} \mathrm{O}+\mathrm{O}_{2}+4 e \rightarrow 4 \mathrm{OH}^{-}
\end{array}
$$

* Corresponding author: robpolder@ robpolder.demon.nl 
With chloride induced corrosion localised or pitting attack develops and anodic sites may be small; locally the potential drops several hundreds of millivolts and the $\mathrm{pH}$ drops to $2-3[16,17]$. Cathodic potentials remain in the more positive ranges; strong potential gradients develop between anodic and cathodic regions.

The basic principle of cathodic protection is shifting the steel/concrete interface potential difference to more negative values, slowing down oxidation reactions (eq.1) and accelerating reduction reactions (eq.2). In concrete, shifts of a few hundred millivolts are sufficient to move corrosion rates to negligible levels [8]. This is due to favourable effects of current flow: increased cathodic reactions produce hydroxyl ions and increase the $\mathrm{pH}$ at the steel/concrete interface and negatively charged chloride ions migrate away from the steel/concrete interface. The current is injected into the concrete from an electrode installed on the concrete surface or in the cross section, called the anode, causing the interfacial potential to shift. At this anode, oxidation reactions take place that consume hydroxyl ions or that oxidise materials at the anode/concrete interface described by the following equations:

$$
\begin{gathered}
4 \mathrm{OH}^{-} \rightarrow 2 \mathrm{H}_{2} \mathrm{O}+4 e \\
M \rightarrow M^{+}+e
\end{gathered}
$$

Reaction (3) may cause acidification and possibly loss of anode/concrete bond by dissolving the hardened cement paste; reaction (4) oxidises galvanic anode materials or carbon particles in conductive coatings. Possible side effects at the cathode are accumulation of alkali ions due to ionic migration; and possibly hydrogen evolution according to an additional cathodic reaction:

$$
2 \mathrm{H}_{2} \mathrm{O}+2 \mathrm{e} \rightarrow \mathrm{H}_{2}+2 \mathrm{OH}^{-}
$$

Hydrogen evolution at the surface of prestressing steel may cause its embrittlement. Reaction (5) can be avoided by limiting the current density at the prestressing (or duct) surface. As this reaction only occurs at very negative potentials, typically $-1100 \mathrm{mV}$ versus SCE, monitoring the steel potential can be used as a safety measure. At more positive potentials than about $-1000 \mathrm{mV}$, only reaction (2) is possible and hydrogen evolution does not occur. High alkali levels may provoke alkali-silica reaction in concrete with reactive aggregates. Both of these adverse side effects occur only at relatively high current densities. For more information on principles and effects see [1]. All reinforcing steel and other metals embedded in the concrete have to be electrically continuous and connected to the cathode circuit; otherwise they will not be protected or may even develop accelerated corrosion due to stray current effects.

\section{Practical aspects}

Two basic types of CP systems have been used: impressed current CP (ICCP) and galvanic (sacrificial)
CP (GCP). The main components are illustrated in Figure 1. In ICCP a low voltage DC power is the source of current flow. The anode consists of a material that is not (or only slowly) consumed, such as activated titanium (covered with noble metal oxides, Mixed Metal Oxide, MMO) or a conductive coating.

Activated titanium has the shape of a mesh embedded in a cementitious overlay installed on the concrete surface; or of fine mesh strips in boreholes in the concrete cross section or in slots cut in the concrete surface; holes and slots are filled with a cementitious grout. Conductive coatings are polymers filled with carbon particles, applied to the concrete surface and usually covered with a (normal) top coat. Primary anodes are metal wires that feed the current into the actual anode material; they should be spaced closely enough to avoid large potential drops in the anode material. Cementitious overlays and conductive coatings should be durably bonded to the concrete surface for good electrical contact. Achieving good bond requires good surface preparation and proper application and curing are essential.

In ICCP systems, the power source and the anodes are connected through isolated copper cables and anodecopper connections. Cable cross sections should be large enough for limited potential drop. Cables need to be redundant in order to avoid system failure due to (single) cable interruptions, e.g. by vandalism; at least two cables should feed anodes as well as cathodes, with connections as far apart as possible within a zone. Power sources are fed from the normal grid or by solar or wind energy, the latter two backed up by batteries.

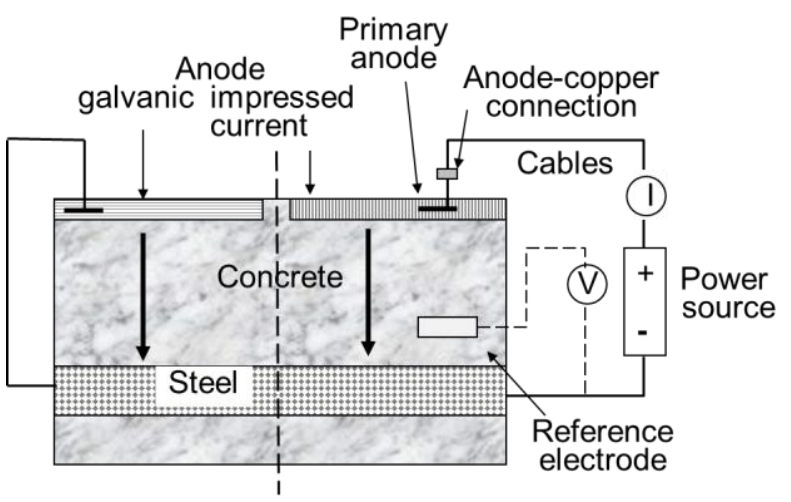

Fig. 1. Main components of galvanic (left) and impressed current (right) CP systems.

In GCP systems the power originates from the electrochemical potential difference between the anode material and the steel. Corrosion of a sacrificial material, normally zinc, provides the current according to

$$
Z n \rightarrow Z n^{2+}+2 e
$$

A GCP system can be made of zinc sheet with an appropriate activator and a conductive adhesive on the concrete surface; or by embedding zinc probes with activator inside cavities or boreholes in the cross section. Activators are needed to keep the zinc corroding; they are proprietary formulations based on alkalinity, 
complexing agents or halides. Zinc anodes are connected to the reinforcement using copper wires.

A CP system can be divided into separately controlled parts called zones, if current densities between different parts of a structure are anticipated to be different or for practical reasons. Current densities are affected by differences in concrete electrical resistivity due to different exposure to precipitation or different cement types having been used [13, 18]. Practical reasons can apply to avoid large zones with poor controllability or a low capacity of available power units. Basic design of CP is based on a current density of 20 $\mathrm{mA} / \mathrm{m}^{2}$ of steel surface, as a rule of thumb. It can be debated if this should concern all steel in the entire concrete cross section or only the steel closest to the surface. Experience shows that most CP systems operate at much lower current densities, typically of $1-5$ $\mathrm{mA} / \mathrm{m}^{2}$ (steel surface). However, the current density per unit of concrete surface area can be quite different. Buildings usually contain less than $1 \mathrm{~m}^{2}$ of steel surface, typically $0.5 \mathrm{~m}^{2}$ per $\mathrm{m}^{2}$ of concrete surface. The steel/concrete density of civil engineering structures can be much higher, in particular in areas with higher stresses, typically 1 or more. In practice, impressed CP current is kept as low as possible by applying a low voltage to limit system degradation and negative side effects, while maintaining sufficient protection. In galvanic systems, the current cannot be externally controlled and the zinc consumption rate is determined by concrete resistivity and steel density, which will determine anode working life. In hybrid systems, in which an impressed current is first applied for some time and then are switched to galvanic mode, anode life is governed by both principles.

Preventive application requires lower (design) current densities, in the range of $0.2-2 \mathrm{~mA} / \mathrm{m}^{2}$, because preventing corrosion is easier than stopping it [8, 19]. Compared to curative systems, less anode material is needed and current distribution is more favourable.

Protection quality is tested by interrupting the current for several hours to one day or more and monitoring the steel potential using a reference electrode (RE). For ICCP, the current is switched off at the power source. For GCP, usually a special section is made that allows switching off; in the other parts of such a system the anode is directly connected to the steel at multiple spots. Upon interrupting the current, the steel potential shifts to more positive values. This test is called a depolarisation test. A steel potential depolarisation (shift) of at least 100 $\mathrm{mV}$ between instant off (which eliminates ohmic drop) and up to 24 hours is the most widely used criterion for sufficient protection [19]. Multiple RE's should be embedded at representative locations in each zone. Regular monitoring consists of depolarisation testing at least twice a year and a visual inspection once a year. Monitoring usually starts as part of a maintenance contract between the owner and the company that installed the system. However, in a substantial number of cases monitoring has not been carried out or has been neglected since the end of the original contract (see below). Increasing numbers of systems are remotely monitored or controlled using dataloggers and modern wireless connection technology. Nowadays more and more systems are being monitored by independent parties, after termination of the original monitoring contract. This implies that proper documentation of the as built system must be available.

\section{Experience}

As mentioned, application of CP in concrete started in Europe by 1985 , in the UK and Italy. The first CP system in The Netherlands was installed in 1986/7 on a concrete cycle lane of the Stadium Viaduct in Rotterdam [13]. It protected $150 \mathrm{~m}^{2}$ of concrete surface in two zones; the anodes were carbon filled polymer cables with a copper wire core with a cast cementitious overlay. A few projects involved this type of anode that was later taken off the market. In 1989, activated titanium anodes in the shape of wires were installed in precast concrete elements in an office facade with corrosion due to chloride ingress from sea water mist. 2500 precast cantilever beams with mixed-in chloride, supporting galleries and balconies in two apartment buildings in Tilburg had titanium strips in holes drilled longitudinally in the beams in 1990. Current distribution between bars in the cross section was studied in the laboratory and between beams in the field [20]. Internal cover measurement was used to avoid anodes and steel being too close or even short-circuited; a distance of $15 \mathrm{~mm}$ was used as minimum distance. Where steel was located too close to the borehole, a polymer isolation pipe was placed around the titanium strip. Two similar projects with 1000 cantilever beams with drilled in titanium strip anodes were made in Groningen in 1997 and 1998. On the beams and roof slabs of the top floors a conductive coating was used instead of drilled in strips. Carbon based conductive coatings were introduced as anode material and were applied to several buildings with mixed-in chloride. A series of seven buildings with columns, beams and slabs with mixed-in chloride and moderate concrete quality were protected with a conductive coating between 1993 and 2000 [13]. The long term performance of some of these early systems is discussed below.

The durability and repair of precast concrete elements with mixed-in chloride developed into a major problem in The Netherlands. In many cases conventional repair was found not to be effective: corrosion and cracking of concrete reappeared within a few years after such repairs. In contrast, CP was found to be an effective and durable solution.

Based on the notion that uniform current distribution was important and would be mainly governed by the electrical resistivity of the concrete, the resistivity of materials used for repairs associated with CP should be similar to that of the parent concrete. This was adopted by the European Standard on CP of concrete [19]. Exposure to rain and solar radiation, e.g. due to orientation of facades, was also considered to have an effect on resistivity and it was suggested as a basis for dividing systems into multiple zones. 
$\mathrm{CP}$ companies and knowledge institutes cooperated to set up a Recommendation published in 1996 by CUR (an organisation roughly comparable to the Concrete Society in the UK) [21]. It addressed curative (not preventative) application to reinforced (not prestressed) concrete and was a typical guideline including technical considerations, test procedures and limiting values. Between 1987 and $1995 \mathrm{CP}$ was applied to 16 structures, mainly buildings with mixed-in chloride, either with activated titanium anode strips in boreholes or with conductive coatings on the concrete surface. This was the pioneering period of CP in The Netherlands.

In the following years, roughly 1996-2004, application of $\mathrm{CP}$ on bridges and other infrastructure developed. In one project, corrosion had induced widespread delamination in a thick wall of a basement of a bridge. Using titanium mesh and shotcrete was rejected due to the possibility of the delaminations hindering current flow to the reinforcement. Subsequently a system based on drilled-in titanium strip anodes was designed. However, during installation, reinforcing bars appeared to be positioned at irregular and unexpected intervals, and many additional holes had to be drilled to avoid short circuits between anode strips and steel bars. In addition, steel continuity was largely absent, such that all rebars had to be connected. Both issues increased the cost of the system significantly. With hindsight, the preliminary investigation should have looked more carefully for the location of rebars and for continuity.

In another case corrosion had developed in the edge beam of a bridge deck above the abutments, due to joints leaking de-icing salt solution. A previous round of superficial repairs did not stop corrosion. Making deeper repairs would have required lifting the deck and taking the bridge out of traffic. CP was selected as a more userfriendly solution. The complication was that posttensioning anchors and tendons were located in the edge beam and concern was raised for overprotection, causing hydrogen evolution and possibly hydrogen embrittlement of the prestressing steel. The problem was addressed by consulting Pietro Pedeferri, who explained that monitoring the potential of the prestressing steel ducts and maintaining it above (more positive than) a safe absolute potential value of $-900 \mathrm{mV}$ versus SCE would preclude hydrogen evolution [8]. This value includes a significant safety margin compared to potentials where hydrogen evolution would really occur (typically $-1100 \mathrm{mV}$ ), as mentioned above. Subsequently $\mathrm{CP}$ was installed using a conductive coating; monitoring the potentials around prestressing ducts and anchors showed them to be well in the safe region. This system worked for almost 20 years until it was replaced by a new conductive coating system in 2015 .

The approach outlined above for CP of prestressed concrete and the same safe absolute potential value were later adopted in the European Standard EN 12696, that was published in 2000 [19]. In addition to supporting CP of prestressed concrete, this Standard also includes preventive application, Cathodic Prevention (CPre), which had been introduced by Pedeferri [8]. The Standard has a performance based approach, rather than being a technical guideline.
Around 2000 galvanic anodes were introduced for CP in concrete in The Netherlands, based on the sacrificial action of zinc. Zinc sheet with an ion-conductive and activating adhesive was applied to various buildings and bridges.

Between 1997 and 2004 a total of 79 structures had CP installed, including buildings with mixed-in or penetrated chloride, bridges and parking structures exposed to de-icing salts and swimming pools. In some cases a single structure contained more than one $\mathrm{CP}$ system, e.g. on the facades and on a basement floor.

By 2004, CP had become a well-accepted method for effective long-term corrosion protection of concrete structures. Involved companies, although relatively small and with economic ups and downs, collectively sponsored a research project by TNO. It comprised setting up a database of $\mathrm{CP}$ cases in the country and further development of numerical models for CP [22]. The database was updated a few times. At the end of 2010, a total of 150 concrete structures in The Netherlands had CP installed, including 105 buildings (apartment blocks, offices, parking and industrial buildings) and 45 bridges and other infrastructure, totalling 85,000 square meters of protected surface [15]. In addition. $65,000 \mathrm{~m}^{2}$ of ground floor elements with mixed-in chloride had been provided with $\mathrm{CP}$.

Out of $150 \mathrm{CP}$ systems, anodes were conductive coating in 65 cases, activated titanium in 50 cases and 35 had galvanic anodes. Good documentation was obtained for 105 systems, usually by the company that installed it and carried out maintenance. Out of 105, 50 cases had been operating for ten years or more and 55 cases for less than ten years. The remaining 45 cases were not documented and/or not monitored, which included most of the galvanic systems.

The survey and analysis of the findings showed a mixed picture of a low rate of overall system degradation and some weak details [15]. Weak details included accelerated corrosion of poorly insulated anode-copper connections; and some cases of degradation of primary anodes in conductive coating systems, both particularly in older ones. It appears that primary anodes should be made of truly inert materials, e.g. noble metals like platinum; less resistant materials are prone to degradation. Some cases of power unit or reference electrode failure were noted. Over time, CP companies improved these weak points, as was borne out by later systems. Just a few cases of overall anode degradation were found. However, local degradation of conductive coatings due to water leakage from overlying parts was an important cause of the need for (some cases of) maintenance. Conductive coating anodes on buildings with relatively sheltered facades were found to last as long as 15 to 20 years. This is shown by the seven buildings mentioned above. By 2013, so 13 to 20 years after their installation, these systems did not comply to the $100 \mathrm{mV}$ depolarisation criterion anymore and were in need of maintenance. However, corrosion or concrete damage were completely absent. Another project with drilled in titanium strip anodes and conductive coating on the top floor showed good performance of the titanium system after 17 years; however, the conductive 
coating part did not work properly anymore. Activated titanium systems performed well over at least 20-25 years in many well-documented cases; working lives of 25 and more years appear very well possible. This experience is in agreement with a recent study on long term performance of CP systems on motorway structures [14], which showed that conductive coating anodes may work for a very long time, also in infrastructural works and despite visible deterioration of the coating.

\section{Market and recent developments}

In 2015 the database on CP systems was updated and an overview is presented. By ultimo 2014, a total of 230 structures had CP with some multiple systems installed, counting a total of $250 \mathrm{CP}$ systems. Figure 2 presents annual and cumulative numbers. Structures comprised 105 buildings, 97 bridges and 44 other structures. Out of these, 103 had conductive coating anodes, 57 titanium and 58 galvanic anodes (29 had other anodes or two types). Owners were The Ministry of Infrastructure (65 systems), lower governments (41) housing companies (48), private collectives (24) and other owners (69). Increasing numbers of cases involved protecting corroding bridge abutments, preventive applications and systems with ground bed anodes; some are illustrated in more detail below.

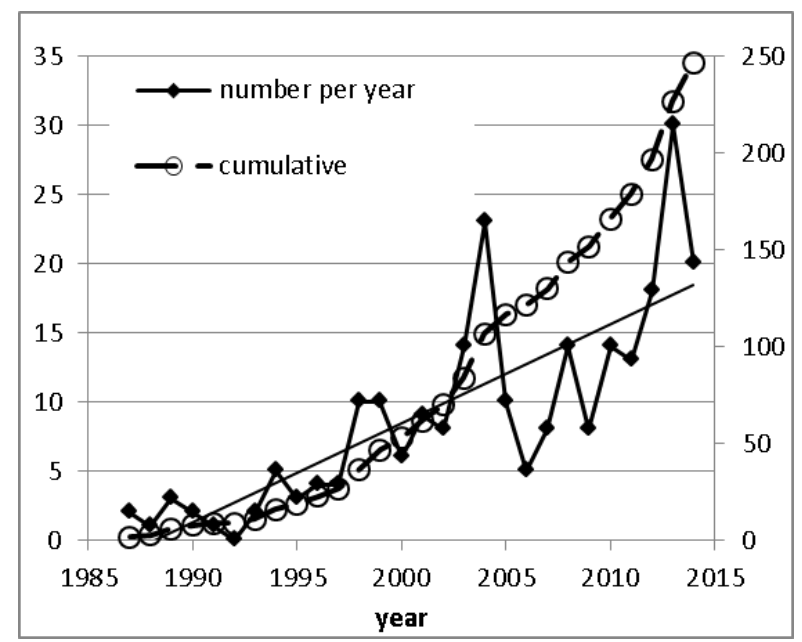

Fig.2. Number of CP systems installed in The Netherlands per year (left Y-axis), cumulative number (right Y-axis) and trend line for number per year.

CP was installed in 30 bridges of similar build up with prefabricated post-tensioned deck girders; for more background and details see [23]. Many beam heads had developed corrosion and spalling due to leakage of overlying expansion joints. Based on existing damage, 1300 beam heads were protected in 2013-2014. CP was applied with a conductive coating (without top coat) on all beam heads with damage plus undamaged adjacent ones, comprising about one-third of the total number. Two RE's were placed in every beam head with $\mathrm{CP}$, one at the outer steel (for depolarisation testing) and one near the post-tensioning anchors (for monitoring the absolute potential). Subsequent operation showed that absolute prestressing anchor potentials were well on the safe side of the $-900 \mathrm{mV}$ criterion. A maintenance contract for 20 years was awarded, including 4-year interval visual inspection of the non-protected beam heads. In 2017 many unprotected elements were found to have developed corrosion and damage; apparently they contained chloride levels that had previously not caused corrosion damage, but they had four years later. Subsequently CP will be installed on those elements.

For a series of new bridges in a motorway around the city of Groningen, corrosion in the abutments would be highly undesired with regard to the effects of repair activities on traffic flow. Consequently, cathodic prevention was installed. Titanium strip anodes cast in mortar blocks were placed between rebar cages and concreted when casting the abutments. Similar anode blocks were placed inside the heads of precast deck beams. Because of the preventive principle, monitoring could be kept at a low level (automated checks of current flow, long interval depolarisation testing). A total of six bridges of this type were provided with CPre between 2012 and 2018.

In recent years, more and more systems are based on anodes in the ground surrounding wall-type structures such as locks and tunnel walls. One example concerns a two-tube tunnel with walls built of soil mixed with cement. Concerns for cracking and durability were countered by installing CPre, with protective current flowing from anodes placed in the ground on either side of the tunnel tubes. Numerical modelling based on ground and "concrete" resistivity was applied to calculate anode-to-anode distances while considering anode-to-wall distances allowed by the right-of-way around the tunnel. After installation and commissioning, several anodes were found to have stopped working due to later works in the area, damaging anode cables. This is a concern for systems with ground anodes.

Based on increased collaboration between CP companies, research institutes and consultants, a CPknowledge centre was founded to promote application of $\mathrm{CP}$. The knowledge centre addresses technical and nontechnical issues, a.o. via working groups, and organises seminars for a wider audience. One working group set up a course for teaching technicians at level 3 of the CP personnel competence Standard [24], which has been held successfully since 2016. Another group proposed an approach to service life prediction of galvanic anodes, based on experience with current densities in practice and Faraday's law, including an efficiency factor. The benefit is that all parties involved now have a common basis for designing and offering galvanic systems for a particular working life. The basis is a model for a decreasing current demand of the reinforcement derived from practical systems: $10 \mathrm{~mA} / \mathrm{m}^{2}$ in the first year, 8 $\mathrm{mA} / \mathrm{m}^{2}$ in the second year, $5 \mathrm{~mA} / \mathrm{m}^{2}$ in the third year and from then on $2 \mathrm{~mA} / \mathrm{m}^{2}$. The efficiency factor is 0.72 (28\% of the zinc does not contribute to current flow to the steel). It is intended to improve this approach based on data from GCP systems. This looks promising, as more and more long term data are being reported [26].

After 30 years of CP application, the "second life" of CP systems should be considered. In particular, older 
conductive coating systems may approach or have already reached the end of their working lives. The question then is how sustained corrosion protection should be achieved. Obviously, replacing the old CP system by a new one is a way. However, supposing that corrosion has not already re-activated, a new system could be designed less conservatively, for example with a lower current demand. Some information exists on residual protection after stopping the current flow [25], where positive effects were documented after short term CP operation. This deserves attention from both research and $\mathrm{CP}$ engineering communities.

Another long-term issue is the accumulated cost of monitoring CP systems, which may be substantial [27]. If it can be shown that after some time of CP operation re-activation of corrosion takes longer or is improbable, increasing the monitoring intervals of systems that have operated well for several years should be considered. Visual inspection remains necessary, but the interval could be increased if remote monitoring is used to guarantee current flow.

\section{Overview and conclusions}

In The Netherlands CP of concrete structures has seen many successful applications and considerable growth, from a few to more than 20 systems being installed per year over the past 30 years. Many different types of systems have been developed, installed and maintained and lessons have been learned. Preliminary investigation should be thorough and must, among others, establish reinforcement positioning and steel continuity. Corrosion due to mixed-in chloride can be effectively stopped with $\mathrm{CP}$, which is hardly possible with conventional repair. Post-tensioned structures can be protected without the risk of damaging prestressing steel, provided a proper design is made and absolute prestressing/duct potentials are monitored. Degradation of components has occurred, but sensitive details are well-known and have been improved. Overall good working lives have been documented for many systems based on long-term field experience. Conductive coatings can remain effective for up to and above 15 years. Activated titanium systems have worked for 25 years and more. Galvanic systems provide a possibility to operate independent of power being available; an approach to predict their working life has been proposed. Installing $\mathrm{CP}$ on bridge joints with corrosion due to de-icing salt leakage is effective and efficient. The preventive application of CP is increasing.

The input of members of the CP-knowledge Centre (www.kb-kenniscentrum.nl) is appreciated.

\section{References}

[1] L. Bertolini, B. Elsener, P. Pedeferri, E. Redaelli, R.B. Polder, Corrosion of Steel in Concrete: Prevention, Diagnosis, Repair, 2nd Edition, Wiley (2013)

[2] R.B. Polder, W.H.A. Peelen, W. Courage, Mat. Corr. 63, 1147 (2012)
[3] G.P. Tilly, J. Jacobs, Concrete repairs performance in service and current practice, BRE Press (2007)

[4] J.H.M. Visser, Q. van Zon, Int. Conf. Concrete Repair, Rehabilitation and Retrofitting III, Taylor \& Francis (2012)

[5] R.F. Stratfull Mat. Perf. 1324 (1974)

[6] J.P. Broomfield, Corrosion of Steel in Concrete Understanding, Investigation and Repair, 2nd Edition, Taylor \& Francis (2006)

[7] J.S. Tinnea, C.B. Cryer, 1st Int. Conf. Heritage and Construction in Coastal and Marine Environment MEDACHS08 (2008)

[8] P. Pedeferri CBM 10391 (1996)

[9] K.A. Grefstad, Eurocorr05, (2005)

[10] O.C.N. Nerland J. Eri, K.A. Grefstad, Ø. Vennesland, Eurocorr07, (2007)

[11] Ch. Haldemann, A. Schreyer, EFC Publication 25 (1998)

[12] F. Wenk, D. Oberhänsli, Eurocorr07 (2007)

[13] R.B. Polder, HERON 433 (1998)

[14] C. Christodoulou, G.K. Glass, J. Webb, S. Austin, C. Goodier, Corr. Sci. 522671 (2010)

[15] R.B. Polder, G. Leegwater, D. Worm, W. Courage Cem. Con. Comp. 4769 (2014)

[16] J. Pacheco, R.B. Polder, A.L.A. Fraaij., J.M.C. Mol, Concrete Solutions, Taylor \& Francis, 147-156 (2011)

[17] M.R. Geiker, R.B. Polder, Mat. Corr., 67600 (2016)

[18] R.B. Polder, CBM 15125 (2001)

[19] EN 12696, Cathodic protection of steel in concrete, (2000)

[20] R.B. Polder, P.C. Nuiten, Mat. Perf. 3311 (1994)

[21] Cathodic protection of reinforcement in concrete structures, in Dutch, CUR 45 (1996)

[22] R.B. Polder, W.H.A. Peelen, F. Lollini, E. Redaelli, L. Bertolini, Mat. Corr. 60130 (2009)

[23] A.J. Hondel, E.L. Klamer, J. Gulikers, R.B. Polder, 4th Int. Conf. Concrete Repair, Rehabilitation and Retrofitting, Taylor \& Francis (2015)

[24] EN-ISO 15257, Cathodic protection Competence levels and certification of cathodic protection persons: basis for certification scheme (2017)

[25] S. Bhuiyan, D.W. Law, P. Nicholls, C. Christodoulou, CBM 162503 (2018)

[26] A.J. van den Hondel, A.W. van den Hondel, Concrete Solutions (2019)

[27] R.B. Polder, Y. Pan, W. Courage, W.H.A. Peelen, HERON 611 (2016) 